\title{
ANALISIS FAKTOR DAN TINGKAT KEPUASAN DITINJAU DARI KUALITAS PRODUK DAN PELAYANAN PADA KONSUMEN SAYURAN ORGANIK DI LOTTE MART KOTA BANDUNG
}

\author{
FACTOR ANALYSIS AND SATISFACTION LEVEL \\ IN TERMS OF PRODUCT QUALITY AND SERVICE QUALITY OF ORGANIC \\ VEGETABLE CONSUMER IN LOTTE MART BANDUNG CITY
}

\author{
Elly Rasmikayati ${ }^{1}$, Bobby Rachmat Saefudin*2, Tuti Karyani' ${ }^{1}$ Kuswarini Kusno${ }^{1}$, \\ Riky Rizkiansyah ${ }^{1}$
}

${ }^{1}$ Fakultas Pertanian, Universitas Padjadjaran, Jl. Ry Bandung-Sumedang KM.21 Jatinangor, 45363

${ }^{2}$ Fakultas Pertanian, Ma'soem University, Jl. Raya Cipacing No. 22 Jatinangor, 45363

*E-mail: bobbyrachmat@masoemuniversity.ac.id

(Diterima 11-01-2020; Disetujui 20-01-2020)

\begin{abstract}
ABSTRAK
Terjadinya peningkatan permintaan sayuran organik mendorong ritel modern untuk dapat memenuhi permintaan tersebut sehingga ketersediaan sayuran organik yang berkualitas harus memadai agar tidak mengecewakan konsumen. Hal lain yang sering kali menjadi perhatian konsumen dalam membeli sayuran organik di ritel modern adalah kualitas pelayanan dalam menyajikan sayuran organik tersebut mengingat harganya yang lebih mahal. Dengan demikian, tujuan dari makalah ini adalah menganalisis tingkat kepuasan konsumen sayuran organik terhadap kualitas produk dan kualitas pelayanan di hypermarket lotte mart kota Bandung yang merupakan salah satu ritel modern yang sudah lama menjual sayuran organik dengan jenis sayuran organik yang beragam. Desain penelitian yang digunakan adalah desain kuantitatif dengan metode survey. Ukuran sampel penelitian adalah 42 orang responden yang diambil menggunakan teknik Systematic Random sampling. Teknik analisis data yang digunakan adalah teknik scoring dan analisis faktor. Hasil penelitian menunjukan bahwa tingkat kepuasan konsumen terhadap kualitas sayuran organik dan kualitas pelayanannya berturut-turut adalah sebesar 75\% dan 77\% sehingga dapat disimpulkan bahwa konsumen sayuran organik merasa puas terhadap kualitas sayuran dan kualitas pelayanan di ritel modern tersebut. Dari hasil analisis faktor didapatkan bahwa faktor kualitas produk sayuran organik yang berpengaruh signifikan terhadap tingkat kepuasaan konsumen adalah adanya bekas gigitan serangga, kemasan yang menarik dan faktor harga yang sesuai kualitas. Sedangkan faktor kualitas pelayanan yang berpengaruh signifikan terhadap tingkat kepuasaan konsumen adalah faktor kesabaran karyawan dalam melayani, tanggapan terhadap keluhan yang mudah dimengerti, kecepatan dan kesiapan melayani konsumen dan faktor pengetahuan karyawan mengenai sayuran organik.
\end{abstract}

Kata kunci: ritel modern, analisis faktor, kepuasan konsumen, sayuran organik, kualitas produk, kualitas pelayanan

\begin{abstract}
An increase in demand for organic vegetables encourages modern retailers to meet these demands so that the availability of quality organic vegetables must be sufficient so as not to disappoint consumers. Another thing that is often of concern to consumers in buying organic vegetables in modern retail is the quality of service in serving these organic vegetables given the higher price. Thus, the purpose of this paper is to analyze the satisfaction level of organic vegetables consumer on product quality and service quality at the Lotte Mart hypermarket in Bandung, which is one of the modern retailers that has long sold organic vegetables with various types of organic vegetables. The research design used is a quantitative design with a survey method. The sample size of the study was 42 respondents taken using the Systematic Random sampling technique. Data analysis technique used is a scoring technique dan factor analysis. The results showed that the level of consumer satisfaction on the quality of organic vegetables and the quality of service respectively were $75 \%$
\end{abstract}


and $77 \%$, so it can be concluded that the consumers of organic vegetables were satisfied with the quality of vegetables and the quality of service in that modern retail. Based on the results of the factor analysis, it was found that the quality factor of organic vegetable products that had a significant effect on the level of consumer satisfaction was the presence of insect bites, attractive packaging and quality-appropriate price factors. While, service quality factors that significantly influence the level of customer satisfaction are factors of employee patience in serving, responses to complaints that are easily understood, speed and readiness to serve consumers and factors of employee knowledge about organic vegetables.

Keywords: modern retail, factor analysis, consumer satisfaction, organic vegetables, product quality, service quality

\section{PENDAHULUAN}

Seiring dengan peningkatan pendapatan masyarakat Indonesia, konsumsi sayuran oleh masyarakatpun meningkat. Berdasarakan data BPS (2013), lebih dari setengah pengeluaran rata-rata masyarakat Indonesia digunakan untuk membeli kelompok barang makanan dan salah satu makanan yang dikonsumsi adalah sayuran, dimana mengkonsumsi sayuran baik untuk kesehatan. Konsumsi sayuran dari tahun ke tahun meningkat, hal ini juga didukung dengan adanya peningkatan akan kesadaran kesehatan (Tabel 1).

Tabel 1. Rata-Rata Konsumsi Sayuran

\begin{tabular}{cccc}
\multicolumn{3}{c}{ Penduduk Indonesia } \\
\hline No & Tahun & $\begin{array}{c}\text { Jumlah Rata-rata } \\
\text { Konsumsi } \\
(\mathrm{Kg} / \text { Kapita/Tahun })\end{array}$ & $\begin{array}{c}\text { Kenaikan } \\
(\%)\end{array}$ \\
\hline 1 & 2013 & 56,9 & - \\
2 & 2014 & 59,5 & 2,6 \\
3 & 2015 & 60,0 & 0,5 \\
4 & 2016 & 60,7 & 0,7 \\
\hline
\end{tabular}

Sumber: Badan Ketahanan Pangan Kementerian Pertanian (2018)

Tabel 1 menunjukkan bahwa ratarata konsumsi sayuran penduduk
Indonesia cenderung mengalami peningkatan.

Konsumen yang mencari barang dengan harga yang lebih murah sudah menjadi salah satu ciri konsumen di Indonesia. Perilaku konsumen yang tidak terlalu memperhatikan keamanan makanan yang dikonsumsi dengan mengkonsumsi makanan seperti sayuran yang ditanam secara konvensional yang banyak mengandung pestisida serta bahan kimia non alami sekarang sudah mulai berubah.

Saat ini terjadi berbagai perubahan dari sisi konsumen, baik dari jenis makanan, cara makan, pola makan, serta teknologi yang digunakan seperti teknologi dalam mengolah makanan. Perubahan tersebut contohnya adalah dahulu konsumen belum mengenal produk pertanian organik tetapi sekarang konsumen telah mengenal apa yang dinamakan produk petanian organik, dimana produk pertanian diusahakan dengan cara mengurangi bahkan 
meniadakan asupan bahan kimia non alami pada proses budidaya pertaniannya. Dari sebelumnya belum terbiasa dengan produk pertanian organik dengan sekarang yang mulai membiasakan mengkonsumsi produk pertanian organik.. Menurut Rasmikayati dkk. (2017) menyikapi tuntutan konsumen tersebut, maka produsen dan market perlu lebih bersikap professional dalam meningkatkan kualitas produk yang dijualnya.

Konsumsi sayur-sayuran yang dahulu masih dengan sayuran hasil pertanian konvensional juga mulai beralih ke hasil pertanian organik. Pertanian organik sekarang ini mendapat perhatian lebih dari masyarakat dunia. Perubahan pola hidup manusia yang sekarang lebih memperhatikan kesehatan dirinya maupun kesehatan lingkungan yang mendorong adanya produk yang sehat dikonsumsi dan aman bagi lingkungan.

Perubahan pola konsumsi produk sayuran konvensional ke organik yang terjadi pada konsumen ini membuat tingkat konsumsi produk organik ikut meningkat yang implikasinya adalah meningkatnya permintaan konsumen terhadap produk sayuran organik.

Terjadinya peningkatan permintaan sayuran organik mendorong ritel modern untuk dapat memenuhi permintaan tersebut sehingga ketersediaan sayuran organik yang berkualitas harus memadai agar tidak mengecewakan konsumen.

Selain kualitas dari produk organik yang disediakan oleh ritel modern, hal lain yang sering kali menjadi perhatian konsumen dalam membeli sayuran organik di ritel modern adalah kualitas pelayanan dalam menyajikan sayuran organik tersebut mengingat harganya yang lebih mahal. Kualitas produk dan pelayanan merupakan atribut yang dianggap penting dalam pencapaian kepuasan konsumen dalam membeli produk yang diinginkannya (Rasmikayati dkk, 2017)

Lotte Mart Festival Citylink salah satu yang menjual lebih banyak sayuran organik di kota Bandung. Di ritel modern tersebut, sayuran organik ditampilkan dengan display yang menarik, dimana sayuran organik di disimpan pada rak berpendingin yang bisa diatur suhunya setiap saat. Hal itu bertujuan selain untuk meningkatkan pelayanan terhadap produk sayuran organik juga untuk menjaga kualitasnya supaya tetap segar dan mampu bertahan untuk disimpan dalam waktu yang lebih lama.

Berdasaran uraian tersebut, tujuan dari penelitian ini adalah menganalisis tingkat kepuasan konsumen sayuran 
organik terhadap kualitas produk dan kualitas pelayanan di hypermarket lotte mart festival citylink kota Bandung yang merupakan salah satu ritel modern yang sudah lama menjual sayuran organik dengan jenis sayuran organik yang beragam.

\section{METODE PENELITIAN}

Objek dalam penelitian ini adalah perilaku pembelian sayuran organik serta kepuasan konsumen sayuran organik di Lotte Mart Festival Citylink. Jenis sayuran organik yang dijual diantaranya, kangkung, bayam, caisim, selada Keriting, pakcoy dan lainnya. Tempat penelitian adalah Lotte Mart Festival Citylink yang beralamat di Jalan Peta nomer 241, Bandung.

Desain yang digunakan dalam penelitian ini adalah desain kuantitatif, sedangkan teknik yang digunakan dalam penelitian ini yaitu survey. Populasi dari penelitian ini adalah seluruh konsumen sayuran organik di Lotte Mart Festival Citylink pada 1 bulan dengan rata-rata jumlah konsumen sebanyak 507 orang per bulan.

Sampel diambil dengan teknik systematic random sampling dimana hanya unsur pertama yang dipilih secara random, sedangkan unsur-unsur berikutnya dipilih secara sistematik menurut suatu pola tertentu.

Berdasarkan rumus pengambilan sampel pada teknik sampel yang digunakan, didapatkan ukuran sampel sebanyak 42 responden dengan interval 3 (Anderson et al., 2016).

Survey dilakukan pada hari Senin sampai Minggu. Responden pertama terpilih secara random setiap harinya. Responden kedua merupakan konsumen keempat setelah konsumen pertama yang dijadikan responden pertama atau selang dua setelah responden pertama. Jika konsumen keempat tidak berkenan untuk diwawancarai maka konsumen ke lima yang dijadikan responden selanjutnya, dan begitu seterusnya.

Operasionalisasi variabel dalam penelitian ini disajikan dalam Tabel 2. 
Tabel 2. Operasionalisasi Varibel Penelitian

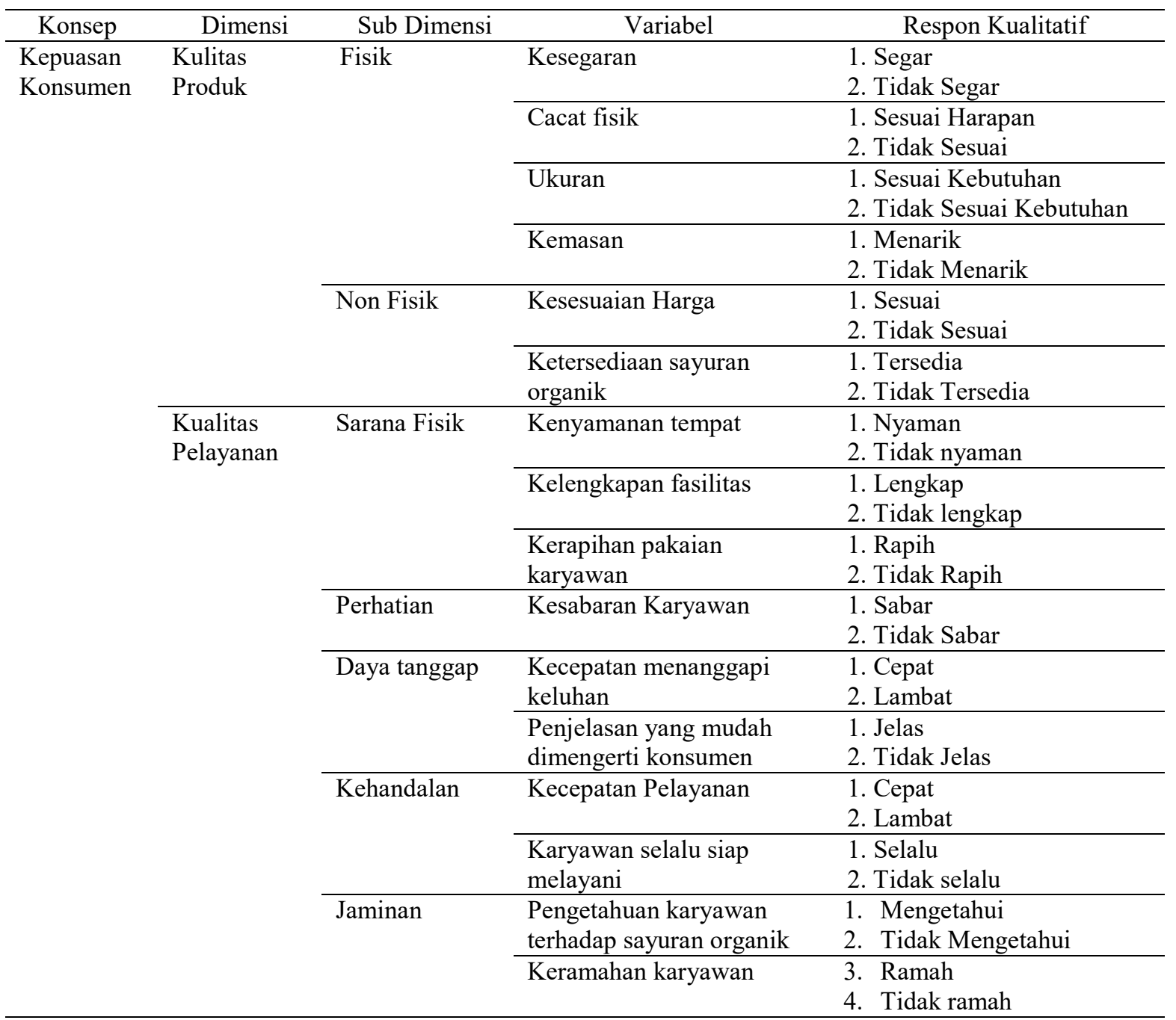

Sumber: De Mooij (2019); Aldosari et al. (2016); Azhar dkk. (2012).

Variabel-variabel kepuasan

konsumen lebih bersifat kualitatif

dibanding kuantitatif. Untuk itu, data-data

kualitatif yang diperoleh di lapangan

dilakukan proses kuantifikasi dengan cara memberikan bobot/skor pada jawaban yang diberikan responden. Skor yang digunakan adalah skala Likert. Jawaban dari responden diberi skor sesuai persepsinya terhadap pernyataan. Bentuk skor jawaban seperti berikut ini:
1. Persepsi sangat tinggi diberi skor 5

2. Persepsi tinggi diberi skor 4

3. Persepsi kurang diberi skor 3

4. Persepsi rendah diberi skor 2

5. Persepsi sangat rendah diberi skor 1

Pemberian skor terhadap pernyataan kemudian dihitung jumlahnya serta persentasenya terhadap nilai maksimal yang diharapkan. Penentuan kepuasan konsumen dilakukan berdasarkan jumlah skor seluruh dimensi kepuasan konsumen 
selanjutnya dibuat persentase terhadap skor harapan maksimum yang dapat dicapai oleh seluruh dimensi.

$\mathrm{I}=100 /$ Jumlah Kelas

Maka $=100 / 5=20$

Hasil (I) $=20$

(Ini adalah intervalnya jarak dari terendah $0 \%$ hingga tertinggi $100 \%$ )

Berikut kriteria interpretasi skornya berdasarkan interval. Dibuat 5 kelas kepuasan konsumen, yaitu:

1. 0 - 20 : Sangat Tidak Puas

2. 20,1 - 40 : Tidak Puas

3. 40,1-60 : Kurang Puas

4. $60,1-80$ : Puas

5. 80,1-100 : Sangat Puas.

Kemudian untuk menganalisis faktor-faktor-faktor terkait kualitas produk dan pelayanan yang berpengaruh terhadap kepuasan konsumen sayuran organik di Lotte Martt digunakan analisis faktor dengan alat bantu software SPSS 23.

\section{HASIL DAN PEMBAHASAN}

Kepuasan konsumen menggambarkan sejauh mana harapan pelanggan terpenuhi baik itu dari kualitas sayuran organik yang deterima maupun kualitas pelayanan yang diterima.

\section{Kepuasan Konsumen Terhadap}

\section{Kualitas Sayuran Organik}

Kualitas sayuran organik yang diterima sesuai dengan harapan konsumen akan menjadikan konsumen puas terhadap sayuran organik yang diterima konsumen. Seperti pada Tabel 3 dengan nilai harapan sebesar 1260, tingkat kepuasan yang di dapat sebesar $75 \%$.

Tabel 3. Kepuasan Konsumen Terhadap Kualitas Sayuran Organik

\begin{tabular}{|c|c|c|c|c|c|c|c|c|c|}
\hline \multirow[b]{2}{*}{ No } & \multirow[b]{2}{*}{ Pernyataan } & \multicolumn{5}{|c|}{ Penilaian } & \multirow[b]{2}{*}{$\begin{array}{l}\text { Jumlah } \\
\text { Nilai }\end{array}$} & \multirow{2}{*}{$\begin{array}{c}\text { Nilai } \\
\text { Maksimal } \\
\text { Harapan }\end{array}$} & \multirow[b]{2}{*}{$\%$} \\
\hline & & $\begin{array}{l}\text { SS } \\
(5)\end{array}$ & $\begin{array}{c}\mathrm{S} \\
(4)\end{array}$ & $\begin{array}{l}\mathrm{KS} \\
(3)\end{array}$ & $\begin{array}{l}\text { TS } \\
(2)\end{array}$ & $\begin{array}{l}\text { STS } \\
(1)\end{array}$ & & & \\
\hline 1 & $\begin{array}{l}\text { Sayuran organik memiliki } \\
\text { kesegaran yang baik }\end{array}$ & 3 & 28 & 11 & 0 & 0 & 160 & 210 & 76 \\
\hline 2 & $\begin{array}{l}\text { Sayuran organik memiliki cacat } \\
\text { fisik bekas gigitan serangga }\end{array}$ & 0 & 23 & 19 & 0 & 0 & 149 & 210 & 71 \\
\hline 3 & $\begin{array}{l}\text { Sayuran organik memiliki ukuran } \\
\text { yang sesuai dengan kebutuhan }\end{array}$ & 2 & 36 & 4 & 0 & 0 & 166 & 210 & 79 \\
\hline 4 & $\begin{array}{l}\text { Kemasan dari sayuran organik } \\
\text { menarik dan aman }\end{array}$ & 0 & 36 & 6 & 0 & 0 & 162 & 210 & 77 \\
\hline 5 & $\begin{array}{l}\text { Harga yang ditawarkan sesuai } \\
\text { dengan kualitas sayuran organik }\end{array}$ & 0 & 31 & 11 & 0 & 0 & 157 & 210 & 75 \\
\hline 6 & Sayuran organik selalu tersedia & 0 & 26 & 16 & 0 & 0 & 152 & 210 & 72 \\
\hline & TOTAL & 5 & 180 & 67 & 0 & 0 & 946 & 1260 & 75 \\
\hline
\end{tabular}

Keterangan: Tingkat Kepuasan dalam persen: 0-20 : Sangat Tidak Puas; 20,1-40 : Tidak Puas; 40,1-60 : Kurang Puas; 60,1-80 : Puas; 80,1-100 : Sangat Puas 
Berdasarkan Tabel 3 dari 6 pernyataan yang dikemukakan semuanya menunjukan tingkat kepuasan yang puas. Konsumen menunjukan kepuasannya terhadap kesegaran sayuran organik yang diterima dengan tingkat kepuasan sebesar $76 \%$.

Kesegaran sayuran organik di Lotte Mart festival Citylink memang selalu terjaga, hal ini dikarenakan sayuran yang dipajang ditempatkan pada tempat yang berpendingin sehingga mengurangi kemungkinan sayuran layu. Meskipun sayuran dikemas menggunakan kemasan plastik, akan tetapi sirkulasi udara tetap terjaga karena pada kemasan diberi lubang agar ada sirkulasi udara pada kemasan. Adapun kejadian sayuran layu hal ini terjadi ketika terdapat sayuran yang sudah lama dipajang dan telat ditarik kembali dari tempat display.

Selain kesegarannya, sayuran organik juga dikenal dengan kualitasnya yang tidak menggunakan pestisida untuk mengurangi gangguan hama maupun penyakit. Hal ini salah satunya ditunjukan dengan adanya bekas gigitan serangga pada sayuran yang menunjukan bahwa sayuran tersebut tidak diberi pestisida pada saat budidaya maupun pasca panen. Pada tabel 3 menunjukan kepuasan konsumen terhadap kualitas sayuran dilihat dari cacat fisik bekas gigitan serangga sebesar $71 \%$. Tingkat kepuasan terhadap kualitas ini merupakan tingkat kepuasan yang paling rendah diantara variabel kepuasan lainnya. Hal ini dikarenakan konsumen tidak banyak menemukan bukti bekas gigitan tersebut. Selain itu sayuran juga telah melewati kegiatan pasca panen dan adanya pembuangan sayuran yang terkena hama tersebut.

Sayuran organik yang ditawarkan dikemas dalam kemasan plastik dengan berat 250 gram. Sayuran yang dikemas seperti itu menjadikan sayuran organik terlihat lebih menarik dan aman karena berada di dalam kemasan, selain itu kemasan plastik juga dibuat semenarik mungkin dengan gambar yang informatif dan menarik. Konsumen merasa puas dengan hal tersebut sebagaimana yang ditunjukan dari persentase tingkat kepuasan terhadap hal tersebut sebesar $77 \%$. Banyaknya sayuran dalam satu kemasan juga sudah dirasa cukup bagi konsumen, bahkan kepuasan konsumen terhadap hal tersebut menjadi yang terbesar sebesar $79 \%$.

Harga yang ditawarkan untuk sayuran organik per kemasan 250 gram sekitar Rp 7.900,-, dengan harga tersebut dirasa sudah sesuai dengan sayuran yang 
ditawarkan. Konsumen memaklumi harga sayuran organik yang diterimanya lebih tinggi dibandingkan dengan harga sayuran non organik. Karena kualitas sayuran yang diterimapun lebih baik.

Tingkat kepuasan konsumen terhadap ketersediaan sayuran organik hanya sebesar $72 \%$, dimana hal tersebut menunjukan bahwa masih terdapat waktu dimana sayuran organik tidak tersedia atau jumlah yang tersedia sedikit. Hal ini terjadi salah satunya ketika barang yang dipesan oleh pihak ritel tidak dikirim oleh pihak suplyer atau terjadi keterlambatan pada pengiriman. Selain itu ketersediaan sayuran organik masih terbatas pada jenis sayuran tertentu, dan sayuran organik yang banyak tersedia adalah jenis sayuran daun seperti kangkung, bayam, caisin dll.

\section{Kepuasan Konsumen Terhadap Kualitas Pelayanan}

Kualitas pelayanan yang dirasakan konsumen sudah dirasa baik dan konsumen merasa puas dengan apa yang mereka terima, hal ini ditunjukan dengan tingkat kepuasan sebesar $77 \%$. Akan tetapi perlu adanya peningkatan untuk memberikan pelayanan yang lebih baik terhadap konsumen.

Kelengkapan fasilitas dan kenyamanan yang diterima konsumen merupakan dua hal yang mendapatkan penilaian sangat puas dari konsumen. Fasilitas yang disediakan lengkap, seperti tersedianya tempat penitipan barang, meja informasi, kereta belanja dengan berbagai ukuran, tempat makan, tempat penimbangan, lemari berpendingin, serta fasilitas lainnya. Selain itu kebersihan tempat belanja juga selalu dijaga agar konsumen selalu merasa nyaman. Petugas kebersihan ada disetiap zona dan selalu menjaga kebersihan. Tempat sampah juga ditempatkan dibeberapa titik yang berpotensi menjadi sumber sampah seperti di tempat penimbangan sayur dan buah serta tempat makan dan di depan toko. Petugas keamananpun ditempatkan di depan toko baik di pintu masuk maupun dekat kasir bahkan ada juga yang berkeliling di area belanja. Hal ini untuk memberikan rasa aman kepada konsumen dan menjaga dari tindak kejahatan terhadap aset toko itu sendiri. Kemanan juga didukung dengan pemakaian kamera pemantau dibeberapa titik.

Setiap karyawan memakai seragam yang telah ditentukan oleh lotte, ada beberapa seragam yang digunakan dan berbeda bagi setiap divisinya. Kerapihan harus selalu dijaga oleh setiap karyawan. Bahkan untuk karyawan bagian sayur dan buah kelengkapan seperti masker dan 
sarung tangan harus digunakan untuk menjaga kebersihan dari sayur dan buah yang ada. Konsumen merasa puas dengan kerapihan karyawan tersebut.

Tabel 4. Kepuasan Konsumen Terhadap Kualitas Pelayanan

\begin{tabular}{|c|c|c|c|c|c|c|c|c|c|}
\hline \multirow[b]{2}{*}{ No } & \multirow[b]{2}{*}{ Pernyataan } & \multicolumn{5}{|c|}{ Penilaian } & \multirow[b]{2}{*}{$\begin{array}{l}\text { Jumlah } \\
\text { Nilai }\end{array}$} & \multirow{2}{*}{$\begin{array}{c}\text { Nilai } \\
\text { Maksimal } \\
\text { Harapan } \\
\end{array}$} & \multirow[b]{2}{*}{$\%$} \\
\hline & & $\begin{array}{l}\mathrm{SS} \\
(5)\end{array}$ & $\begin{array}{c}\mathrm{S} \\
(4)\end{array}$ & $\begin{array}{l}\mathrm{KS} \\
(3)\end{array}$ & $\begin{array}{l}\text { TS } \\
(2)\end{array}$ & $\begin{array}{l}\text { STS } \\
(1)\end{array}$ & & & \\
\hline 1 & $\begin{array}{l}\text { Tempat berbelanja } \\
\text { memberikan rasa nyaman }\end{array}$ & 3 & 39 & 0 & 0 & 0 & 171 & 210 & 81 \\
\hline 2 & $\begin{array}{l}\text { Tempat berbelanja memiliki } \\
\text { fasilitas yang lengkap }\end{array}$ & 7 & 35 & 0 & 0 & 0 & 175 & 210 & 83 \\
\hline 3 & Pakaian karyawan terlihat rapih & 0 & 37 & 5 & 0 & 0 & 163 & 210 & 78 \\
\hline 4 & $\begin{array}{l}\text { Karyawan sabar dalam melayani } \\
\text { konsumen }\end{array}$ & 0 & 31 & 11 & 0 & 0 & 157 & 210 & 75 \\
\hline 5 & $\begin{array}{l}\text { Karyawan cepat dalam menanggapi } \\
\text { keluhan konsumen }\end{array}$ & 0 & 29 & 13 & 0 & 0 & 155 & 210 & 74 \\
\hline 6 & $\begin{array}{l}\text { Penjelasan karyawan terhadap } \\
\text { keluhan yang disampaikan mudah } \\
\text { dimengerti }\end{array}$ & 0 & 37 & 5 & 0 & 0 & 163 & 210 & 78 \\
\hline 7 & $\begin{array}{l}\text { Karyawan cepat dan selalu siap } \\
\text { melayani konsumen }\end{array}$ & 0 & 30 & 12 & 0 & 0 & 156 & 210 & 74 \\
\hline 8 & $\begin{array}{l}\text { Pengetahuan karyawan terhadap } \\
\text { sayuran organik sudah mumpuni }\end{array}$ & 0 & 26 & 16 & 0 & 0 & 152 & 210 & 72 \\
\hline 9 & $\begin{array}{lrl}\text { Karyawan } & \text { ramah } & \text { dalam } \\
\text { memberikan pelayanan }\end{array}$ & 0 & 35 & 7 & 0 & 0 & 161 & 210 & 77 \\
\hline & TOTAL & 10 & 299 & 69 & 0 & 0 & 1453 & 1890 & 77 \\
\hline
\end{tabular}

Selain kerapihan pakaian, kesabaran serta keramahan karyawan dalam malayani konsumen juga menjadi hal yang disoroti konsumen sebagai bentuk pelayanan yang diharapkan. Meskipun kesabaran dan keramahan merupakan hal yang bisa berbeda pada masing masing karyawan. Akan tetapi konsumen merasa puas dengan keramahan dan kesabaran pelayanan dari karyawan.

Kecepatan karyawan dalam melayani dinilai lebih baik dibandingkan dengan kecapatan karyawan dalam menanggapi keluhan dari konsumen. Seperti yang tertulis pada Tabel 4 dimana tingkat kepuasan konsumen terhadap kecepatan pelayanan lebih besar dibandingkan dengan tingkat kepuasan konsumen terhadap kecepatan karyawan dalam menanggapi keluhan konsumen.

Terpaut jauh antara kepuasan konsumen terhadap kecepatan karyawan dalam menanggapi keluhan konsumen dengan tingkat kepuasan terhadap penjelasan karyawan mengenai keluhan yang disampaikan konsumen. Akan tetapi pengetahuan karyawan terhadap sayuran organik masih belum mumpuni. Meskipun konsumen mudah mengerti dengan apa yang dijelaskan, akan tetapi penjelasannya 
dirasa belum memuaskan pertanyaan dari konsumen.

\section{Faktor-Faktor yang Menentukan}

Tingkat Kepuasan Konsumen Sayuran

\section{Organik}

Berdasarkan Tabel 5, pada komponen/grup 1 menunjukkan bahwa faktor kualitas produk sayuran organik yang berpengaruh signifikan terhadap tingkat kepuasan konsumen sayuran organik adalah faktor/variabel yang memiliki nilai loading factor $\geq 0,5$ (Yamin dalam Rasmikayati dan Saefudin, 2017) yaitu faktor adanya cacat fisik bekas gigitan serangga, kemasan dari sayuran organik menarik dan aman, dan faktor harga yang ditawarkan sesuai dengan kualitas sayuran organik. Sementara itu pada komponen/grup 2, faktor kualitas pelayanan di Lotte Mart yang berpengaruh signifikan terhadap tingkat kepuasan konsumen sayuran organik adalah faktor karyawan sabar dalam melayani konsumen, penjelasan karyawan terhadap keluhan yang disampaikan mudah dimengerti, karyawan cepat dan selalu siap melayani konsumen, dan pengetahuan karyawan terhadap sayuran organik sudah mumpuni.
Konsumen sayuran organik di Lotte Mart sudah mengetahui bahwa ciri fisik adanya bekas gigitan seranggga pada sayuran adalah pertanda yang paling mudah diketahui untuk menegaskan bahwa produk sayuran tersebut bebas dari residu pestisida kimia dan hal ini mempengaruhi tingkat kepuasan konsumen untuk membeli produk sayuran yang sehat. Merujuk kepada Bishnoi dan Kumar (2017) bahwa kesadaran konsumen akan kesehatan dan keamanan produk makanan di mana hal ini dapat mempengaruhi persepsi konsumen dalam membeli produk makanan organik. Kemudian Aertsens et al. (2011) menambahkan bahwa motivasi terkuat untuk mengonsumsi sayuran organik adalah bahwa sayuran tersebut diproduksi tanpa pestisida sintetis, lebih baik bagi lingkungan, lebih sehat, berkualitas lebih tinggi, dan rasanya lebih enak. Lebih jauh lagi, saat ini para remaja sebagai generasi muda sudah mulai memiliki persepsi dan minat yang baik untuk beragribisnis dan mengkonsumsi sayuran organik (Pardian, 2017). Rasmikayati dkk. (2017) menambahkan bahwa ada beberapa faktor pendorong petani muda terlibat dalam agribisnis, yaitu faktor lembaga penyuluhan, perusahaan agribisnis, komunitas dan dukungan keluarga. 
Tabel 5. Hasil Analisis Faktor yang Berpengaruh Signigikan terhadap Tingkat Kepuasan Konsumen Sayuran Organik

\begin{tabular}{|c|c|c|c|}
\hline \multirow[t]{2}{*}{ Dimensi } & \multirow[t]{2}{*}{ Variabel } & \multicolumn{2}{|c|}{$\begin{array}{l}\text { Komponen/Grup } \\
\text { (Loading factor) }\end{array}$} \\
\hline & & 1 & 2 \\
\hline \multirow{6}{*}{$\begin{array}{l}\text { Kualitas } \\
\text { produk }\end{array}$} & Sayuran organik memiliki kesegaran yang baik & $-0,227$ & \\
\hline & Sayuran organik memiliki cacat fisik bekas gigitan serangga & 0,531 & \\
\hline & Sayuran organik memiliki ukuran yang sesuai dengan kebutuhan & $-0,091$ & \\
\hline & Kemasan dari sayuran organik menarik dan aman & 0,570 & \\
\hline & Harga yang ditawarkan sesuai dengan kualitas sayuran organik & 0,685 & \\
\hline & Sayuran organik selalu tersedia & 0,168 & \\
\hline \multirow{9}{*}{$\begin{array}{l}\text { Kualitas } \\
\text { pelayanan }\end{array}$} & Tempat berbelanja sudah memberikan rasa nyaman & & $-0,312$ \\
\hline & Tempat berbelanja memiliki fasilitas yang lengkap & & $-0,009$ \\
\hline & Pakaian karyawan terlihat rapih & & $-0,011$ \\
\hline & Karyawan sabar dalam melayani konsumen & & 0,781 \\
\hline & Karyawan cepat dalam menanggapi keluhan konsumen & & 0,453 \\
\hline & $\begin{array}{l}\text { Penjelasan karyawan terhadap keluhan yang disampaikan mudah } \\
\text { dimengerti }\end{array}$ & & 0,610 \\
\hline & Karyawan cepat dan selalu siap melayani konsumen & & 0,648 \\
\hline & Pengetahuan karyawan terhadap sayuran organik sudah mumpuni & & 0,640 \\
\hline & Karyawan ramah dalam memberikan pelayanan & & 0,028 \\
\hline
\end{tabular}

Ket.: Extraction Method: Principal Component Analysis.

Rotation Method: Varimax with Kaiser Normalization.

Rotation converged in 3 iterations.

Nilai loading faktor pada grup yang lain sengaja dihilangkan untuk memudahkan pengelompokkan.

Terkait faktor kemasan dari sayuran organik menarik dan aman, Lotte Mart menyediakan beberapa jenis sayuran yang tersedia dalam label organik maupun non organik, seperti angkung, bayam, caisim, pakcoy dan selada. Terdapat perbedaan dari keduanya dalam pengemasan produk. Sayuran organik dikemas dengan pembungkus plastik yang diberi gambar merk dan informasi produk, plastik pembungkus tidak tertutup namun terbuka di salah satu bagiannya. Satu kermasan sayuran organik beratnya 250 gram. Penyimpanan sayuran organik di rak display disusun dengan cara digantung pada alat yang sudah disediakan dengan rapih. Sedangkan sayuran non organik tidak dikemas dengan plastik pembungkus. Sayuran non organik hanya diikat dengan plastik seperti selotip, tidak seperti sayuran organik yang dibungkus dengan plastik kemasan yang menarik dan hanya disimpan di bagian bawah rak dengan cara ditumpuk. Akan tetapi tidak ditumpuk secara berlebihan agar sayuran tidak rusak. Satu ikat sayuran non organik beratnya sebesar 150-200 gram. Seperti yang terlihat pada Gambar 1 . 

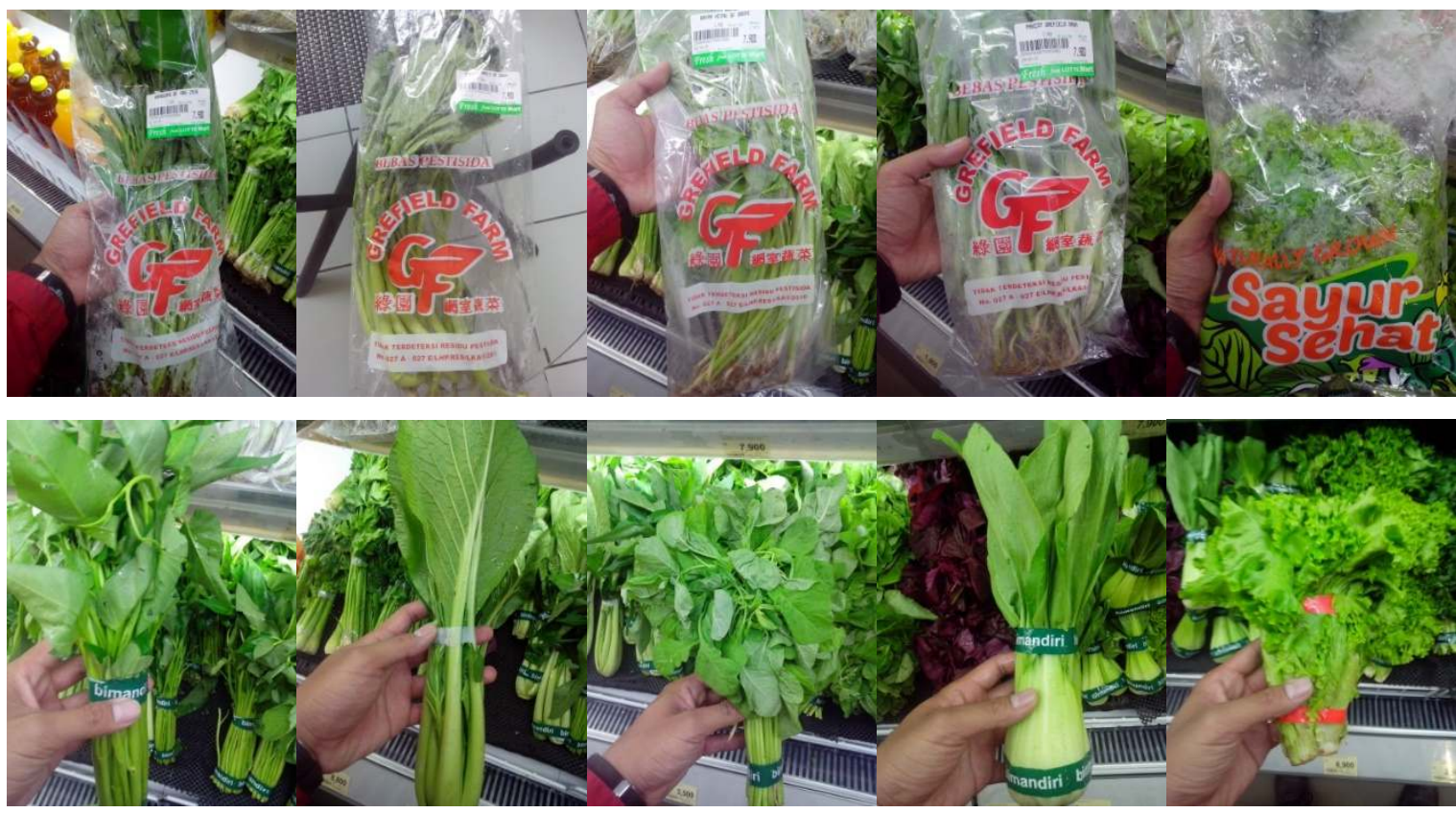

Gambar 1. Tampilan Sayuran di Lotte Mart: Kangkung, Caisim, Bayam, Pakcoy dan Selada Keriting (Gambar Atas: Sayuran Oganik; Gambar Bawah: Sayuran Non Organik

Sementara itu mengenai faktor harga sayuran organik di Lotte Mart, harga yang ditawarkan untuk sayuran organik dan non organik berbeda dimana sayuran organik harganya cenderung lebih tinggi. Salah satu contohnya adalah sayuran organik kangkung, caisim, bayam dan pakcoy yang dijual Rp 7.900,-/pack, sedangkan untuk sayuran yang sama namun non organik dijual lebih murah seperti caisim, kangkung dan pakcoy Rp 3.500,-/ikat serta bayam Rp 1.900,-/ikat. Harga tersebut dirasa sudah sesuai dengan kualitas sayuran yang ditawarkan dan mempengaruhi tingkat kepuasan konsumen Lotte Mart yang ingin mendapatkan produk sayuran organik yang berkualitas. Hal ini sejalan dengan pernyataan Natawidjaja dkk. (2017) bahwa kepuasan konsumen terhadap suatu produk mempengaruhi kesediaan membayar konsumen untuk produk yang memiliki kualitas yang lebih baik.

Sementara itu dari segi faktor kualitas pelayanan yang berpengaruh terhadap kepuasan konsumen, faktor kesabaran karyawan dalam melayani, tanggapan terhadap keluhan yang mudah dimengerti, kecepatan dan kesiapan melayani konsumen dan faktor pengetahuan karyawan mengenai sayuran organik menjadi hal yang berpengaruh terhadap kepuasan konsumen sayuran organik. Hal ini sejalan dengan hasil penelitian Utami dan Jatra (2015) yang mengungkapkan bahwa kualitas layanan 
secara keseluruhan (bukti fisik, keandalan, daya tanggap, jaminan, dan empati) dan pengaruh positif yang signifikan terhadap kepuasan pelanggan.

\section{DAFTAR PUSTAKA}

Aertsens, J., Mondelaers, K., Verbeke, W., Buysse, J., \& Van Huylenbroeck, G. (2011). The influence of subjective and objective knowledge on attitude, motivations and consumption of organic food. British food journal, 113(11), 1353-1378.

Aldosari, M., Ibrahim, Y., Manab, N. B. A., Al-Matari, E. M., \& Alotaibi, E. A. (2016). Linking cooperative health insurance service characteristics to expatriates' satisfaction: Mediating role of customer knowledge. International Review of Management and Marketing, 6(4), 1013-1019.

Anderson, D. R., Sweeney, D. J., Williams, T. A., Camm, J. D., \& Cochran, J. J. (2016). Statistics for business \& economics. Nelson Education.

Azhar, A. R., Salehuddin, M. M., \& Saiful, M. F. B. (2012). Customer satisfaction with hypermarket fresh food's characteristics. Journal of Tourism, Hospitality and Culinary Arts, 4(1), 17-37.

Badan Ketahanan Pangan Kementerian Pertanian. 2018. Direktori Perkembangan Konsumsi Pangan 2018. Kementerian Pertanian.

BPS. (2013). Produk Domestik Bruto Per Kapita, Produk Nasional Bruto Per Kapita dan Pendapatan Nasional Per Kapita, 2000-2013. http://www.bps.go.id/.

Bishnoi, V. K., \& Kumar, P. (2017). Role of health consciousness and food safety concern in buying organic food products. International Journal of Advanced Research and Development, 2(4), 312-318.

De Mooij, M. (2019). Consumer behavior and culture: Consequences for global marketing and advertising. SAGE Publications Limited.

Natawidjaja, R. S., Sulistiowaty, L., Kusno, K., Aryani, D., \& Rachmat, B. (2017). Analisis Preferensi, Kepuasan, dan Kesediaan Konsumen Membayar Beras Di Kota Bandung. Diakses melalui: http://repository.unsri.ac.id/10520/

Pardian, P. (2017). Persepsi Dan Minat Petani Muda Dalam Budidaya Sayuran Swiss Chard Organik. Dharmakarya, 6(3). Diakses melalui:

http://journal.unpad.ac.id/dharmaka rya/article/view/14817.

Rasmikayati, E., Pardian, P., Hapsari, H., Ikhsan, R. M., \& Saefudin, B. R. (2017). Kajian Sikap dan Perilaku Konsumen dalam Pembelian Kopi Serta Pendapatnya Terhadap Varian Produk Dan Potensi Kedainya. Mimbar Agribisnis: Jurnal Pemikiran Masyarakat Ilmiah Berwawasan Agribisnis, 3(2), 117133.

DOI:

http://dx.doi.org/10.25157/ma.v3i2. 563.

Rasmikayati, E., \& Saefudin, B. R. (2018). Confirmatory Factor Analysis: Faktor-Faktor Penentu Agribisnis Mangga Di Kabupaten Majalengka Berdasarkan Penguasaan Lahannya. Jurnal Agribisnis Terpadu, 4(1). DOI: http://dx.doi.org/10.33512/jat.v11i1 .5088 .

Rasmikayati, E., Setiawan, I., \& Saefudin, B. R. (2017). Kajian Karakteristik, Perilaku dan Faktor Pendorong Petani Muda Terlibat dalam 
Agribisnis Pada Era Pasar Global. Mimbar Agribisnis: Jurnal Pemikiran Masyarakat Ilmiah Berwawasan Agribisnis, 3(2), 134149. DOI: http://dx.doi.org/10.25157/ma.v3i2. 565.

Rasmikayati, E., Sulistyowati, L., \& Saefudin, B. R. (2017). Risiko Produksi Dan Pemasaran Terhadap Pendapatan Petani Mangga: Kelompok Mana Yang Paling Berisiko. Mimbar Agribisnis: Jurnal Pemikiran Masyarakat Ilmiah Berwawasan Agribisnis, 3(2), 105-116. DOI: http://dx.doi.org/10.25157/ma.v3i2. 564.
Utami, I. A. I. S., \& Jatra, I. M. (2015). Pengaruh kualitas layanan terhadap kepuasan pelanggan restoran Baruna Sanur. E-Jurnal Manajemen, 4(7). 